\title{
SOLUSI PENDEKATAN PERSAMAAN GELOMBANG FRAKSIONAL NON LINEAR MENGGUNAKAN NEW VERSION OF OPTIMAL HOMOTOPY ASYMPTOTIC METHOD
}

\author{
Approximation Solution of Non Linear Fractional Wave Equation Using \\ New Version of Optimal Homotopy Asymptotic Method
}

\author{
Faiqul Fikri $^{*}$, Eddy Djauhari ${ }^{2}$, Endang Rusyaman $^{3}$ \\ 1,2 Program Studi Matematika, FMIPA, Universitas Padjadjaran \\ Jl. Raya Bandung Sumedang KM 21 Jatinangor Sumedang 45363, Indonesia \\ e-mail:1*faiqulfikri2@gmail.com ; 22eddy.djauhari@unpad.ac.id ; 3 rusyaman@unpad.ac.id \\ Corresponding author*
}

\begin{abstract}
Abstrak
Persamaan diferensial non-linear dengan orde turunan fraksional merupakan model matematika yang banyak digunakan dalam memodelkan fenomena fisik, salah satu penggunaan model tersebut adalah persamaan gelombang fraksional nonlinear. Banyak metode untuk menyelesaikan persamaan diferensial parsial fraksional nonlinear non homogen, salah satunya adalah New Version of Optimal Homotopy Asymptotic Method yang dikembangkan oleh Liaqat Ali pada 2016. Penulis akan menggunakan metode ini untuk menyelesaikan persamaan gelombang fraksional nonlinear yang telah ditentukan, sehingga dapat diamati kekonvergenan barisan fungsi solusi pendekatannya dan dapat diamati bahwa fungsi solusi pendekatan persamaan gelombang fraksional nonlinear menggunakan New Version of Optimal Homotopy Asymptotic Method lebih sederhana dan memiliki nilai galat menggunakan Mean Absolute Percentage Error yang dikategorikan sangat baik.
\end{abstract}

Kata Kunci : Galat, Konvergen, New Version of Optimal Homotopy Asymptotic Method, Persamaan Gelombang Fraksional Non Linear.

\begin{abstract}
Non-linear differential equations with fractional derivative order are mathematical models that are widely used in modeling physical phenomena, one of the applications of these models is non-linear fractional wave equations. Many methods for solving non-linear fractional partial differential equations, one of which is the New Version of Optimal Homotopy Asymptotic Method which is developed by Liaqat Ali in 2016. The author will use this method to solve non-linear fractional wave equations predetermined, so that the convergence of function of the approximation solution non-linear fractional wave equation can be observed and it can be observed that the function of approximation solution of non-linearfractional wave equation solution using the New Version of Optimal Homotopy Asymptotic Method is simple and has a value error using Mean Absolute Percentage Error which is categorized very well.
\end{abstract}

Keywords: Convergent, Error, New version of Optimal Homotopy Asymptotic method, Non Linear Fractional Wave equation. 


\section{PENDAHULUAN}

Permasalahan-permasalahan dalam dunia teknik dan industri dapat diselesaikan dengan melihat fenomena fisik yang terjadi dan dimodelkan menggunakan model matematika. Persamaan diferensial parsial nonlinear merupakan salah satu model matematika yang banyak digunakan untuk menyelesaikan fenomena fisik nonlinear yang terjadi [11], [18], [19].

Persamaan diferensial parsial nonlinear beberapa diantaranya memiliki orde fraksional dimana dalam penggunaannya menggunakan konsep dasar dari kalkulus fraksional [1], [9]. Beberapa model matematika yang menggunakan persamaan diferensial parsial nonlinear adalah persamaan dinamika gas [4], [6], persamaan klein gordon [15], persamaan burger's [12], persamaan perpindahan panas[14], [20], dan persamaan gelombang fraksional nonlinear [2], [5], [14].

Solusi atau penyelesaian dari persamaan diferensial parsial fraksional nonlinear sulit dicari menggunakan metode analitik sederhana [20], oleh karena itu untuk menyelesaikannya digunakan metode numerik, metode analitik perturbasi, metode analitik asimtotik dan sebagainya yang memberikan solusi berupa solusi pendekatan [13].

Beberapa metode matematika yang memberikan solusi terbaik untuk permasalahan nonlinear diantaranya adalah Homotopy Analysis Method [16], Homotopy Perturbation Method [10] dan Optimal Homotopy Asymptotic Method [20]. Optimal Homotopy Asymptotic Method yang selanjutnya disebut OHAM-1 pertama kali diperkenalkan oleh Marinca dan Herişanu [20], kemudian digunakan untuk menyelesaikan permasalahan-permasalahan nonlinear lainnya [5], [12], [14], [15], [20].

Pada 2016, OHAM-1 dikembangkan oleh Ali dkk [7] yang kemudian disebut dengan New Version of Optimal Homotopy Asymptotic Method atau OHAM-2 untuk menyelesaikan permasalahan nilai batas yang berbentuk persamaan diferensial biasa. Ali mengklaim bahwa OHAM-2 memberikan langkah penyelesaian yang lebih sederhana dan memberikan solusi yang lebih akurat dibandingkan OHAM-1.

Motivasi penulis membuat paper ini adalah menggunakan OHAM-2 untuk mencari solusi pendekatan dari persamaan gelombang fraksional nonlinear, menganalisis kekonvergenan barisan fungsi solusinya, lalu membandingkan fungsi solusi pendekatannya dengan OHAM-1 terhadap solusi eksak menggunakan MAPE [17] untuk mengetahui apakah pada persamaan diferensial parsial, OHAM-2 memberikan solusi yang lebih akurat dibandingkan OHAM-1.

\section{METODE PENELITIAN}

\subsection{Persamaan Gelombang Fraksional Non Linear}

Penelitian tentang persamaan gelombang telah banyak dilakukan dengan bentuk persamaan yang berbeda-beda, pada paper ini akan diteliti persamaan gelombang yang sebelumnya diteliti oleh Ghazanfari [2] dan Ullah [5] dengan bentuk

$$
\begin{gathered}
\frac{\partial^{\alpha} u(x, t)}{\partial x^{\alpha}}=F(u(x, t)) \frac{\partial^{2} u(x, t)}{\partial t^{2}}+f(x, t), \quad 1<\alpha \leq 2, t \leq 1,0 \leq x \leq 1 \\
u(0, t)=y_{1}(t), \frac{\partial}{\partial x} u(0, t)=y_{2}(t) .
\end{gathered}
$$

\subsection{Optimal Homotopy Asymptotic Method (OHAM-1)}

Metode ini diperkenalkan oleh Marinca dan Herişanu pada 2008 [20]. Langkah dari Optimal Homotopy Asymptotic Method (OHAM-1) adalah sebagai berikut,

1. Misalkan terdapat persamaan gelombang fraksional nonlinear dengan bentuk

$$
L(u(x, t))+N(u(x, t))+g(x, t)=0
$$

dimana $u(x, t)$ merupakan fungsi yang tidak diketahui, $g(x, t)$ merupakan fungsi analitik yang diketahui, $L$ merupakan operator linear, dan $N$ merupakan operator non linear. 
2. Kemudian definisikan fungsi homotopy $\mathrm{H}\left(v\left(x, t, p, c_{i}\right)\right): \Omega \times[0,1] \rightarrow \mathbb{R}$ sebagai berikut

$$
\begin{aligned}
\mathrm{H}\left(v\left(x, t, p, c_{i}\right)\right) & =(1-p)\left(L\left(v\left(x, t, p, c_{i}\right)\right)+g(x, t)\right) \\
& =H\left(x, t, p, c_{i}\right)\left(L\left(v\left(x, t, p, c_{i}\right)\right)+N\left(v\left(x, t, p, c_{i}\right)\right)+g(x, t)\right)
\end{aligned}
$$

dimana $p \in[0,1]$ merupakan parameter kecocokan, $c_{i}$ merupakan parameter kontrol kekonvergenan, $H\left(x, t, p, c_{i}\right)$ merupakan fungsi bantu yang memenuhi $H\left(x, t, p, c_{i}\right) \neq 0$ untuk $p \neq 0$ dan $H\left(x, t, p, c_{i}\right)=0$ untuk $p=0$, dan $v\left(x, t, p, c_{i}\right)$ merupakan fungsi yang tidak diketahui. Dapat diperhatikan ketika $p=0$ maka diperoleh

$$
v\left(x, t, 0, c_{i}\right)=u_{0}(x, t)
$$

Dan ketika $p \neq 0$ maka

$$
v\left(x, t, 1, c_{i}\right)=u(x, t)
$$

(4) dan (5) menunjukkan bahwa nilai dari $v\left(x, t, p, c_{i}\right)$ bergerak dari $u_{0}(x, t)$ ke $u(x, t)$ seiring pergerakan $p$ dari 0 ke 1 .

3. Mendefinisikan fungsi bantu $H\left(x, t, p, c_{i}\right)$

$$
H\left(x, t, p, c_{i}\right)=p c_{1}+p^{2} c_{2}+p^{3} c_{3}+\cdots+p^{i} c_{i}, i=1,2,3, \ldots
$$

4. Mengekspansikan $v\left(x, t, p, c_{i}\right)$ dan $N\left(v\left(x, t, p, c_{i}\right)\right)$ menggunakan deret Taylor di sekitar $p=0$ sehingga diperoleh

$$
v\left(x, t, p, c_{i}\right)=u_{0}(x, t)+\sum_{m=1}^{\infty} u_{m}\left(x, t, p, c_{i}\right) p^{m}
$$

dan

$$
N\left(v\left(x, t, p, c_{i}\right)\right)=N_{0}(x, t)+\sum_{m=1}^{\infty} N_{m}\left(x, t, p, c_{i}\right) p^{m}
$$

Kemudian dengan mensubstitusikan (7) dan (8) ke (3) dan mengelompokkan parameter kecocokan $p$ dengan pangkat yang sama, diperoleh orde dari penyelesaian masalah sebagai berikut.

Masalah orde ke-nol

$$
L\left(u_{0}(x, t)\right)=-g(x, t)
$$

Masalah orde ke-satu

$$
L\left(u_{1}\left(x, t, c_{i}\right)\right)=c_{1} N_{0}\left(u_{0}\left(x, t, c_{i}\right)\right)
$$

Masalah orde ke-dua

$$
L\left(u_{2}\left(x, t, c_{i}\right)\right)=\left(c_{1}+c_{1}^{2}+c_{2}\right)\left(N_{0}\left(u_{0}\left(x, t, c_{i}\right)\right)\right)+c_{1} N_{1}\left(u_{0}\left(x, t, c_{i}\right), u_{1}\left(x, t, c_{i}\right)\right)
$$

Dan seterusnya.

Solusi pendekatan diperoleh dengan menghitung orde masalah ke- $m$ sebagai berikut

$$
\tilde{u}\left(x, t, c_{1}, c_{2}, \ldots, c_{m}\right)=u_{0}(x, t)+\sum_{i=1}^{m} u_{i}\left(x, t, c_{1}, c_{2}, \ldots, c_{i}\right)
$$

5. Menghitung nilai residu untuk mendapatkan nilai dari parameter kekonvergenan $c_{i}$. Banyak metode untuk menghitung nilai residu, salah satunya adalah metode Galerkin's [3]. Dengan mensubstitusikan (12) ke (2) diperoleh fungsi residu:

$$
R\left(x, t, c_{1}, c_{2}, \ldots, c_{m}\right)=L\left(\tilde{u}\left(x, t, c_{1}, c_{2}, \ldots, c_{m}\right)\right)+N\left(\tilde{u}\left(x, t, c_{1}, c_{2}, \ldots, c_{m}\right)\right)+g(x, t)
$$

kemudian mendefinisikan fungsi bantu residu 


$$
J\left(c_{1}, c_{2}, c_{3}, \ldots, c_{m}\right)=\int_{a}^{b} \int_{c}^{d} R\left(x, t, c_{1}, c_{2}, c_{3}, \ldots, c_{m}\right) d x d t
$$

dan meminimumkannya sehingga diperoleh nilai parameter kekonvergenan $c_{i}$ sebagai berikut

$$
\frac{\partial J}{\partial c_{i}}=0
$$

\subsection{New Version of Optimal Homotopy Asymptotic Method (OHAM-2)}

OHAM-2 dikembangkan oleh Ali [7] menggunakan konsep dasar dari OHAM-1, dengan memperhatikan persamaan gelombang fraksional nonlinear yang sama seperti (2), langkah dari New Version of Optimal Homotopy Asymptotic Method (OHAM-2) adalah sebagai berikut,

1. Mendefinisikan $u_{0}(x, t)$ sebagai nilai awal dari $u(x, t)$ sebagai berikut

$$
L\left(u_{1}\right)=c_{1} N_{0}
$$

2. Mendefinisikan fungsi $v\left(x, t, p, c_{i}\right)$ ke dalam bentuk partikulir

$$
v\left(x, t, p, c_{i}\right)=u_{0}(x, t)+p u_{1}(x, t)
$$

dimana $p \in[0,1]$ merupakan parameter kecocokan. Sehingga solusi pendekatan persamaan gelombang fraksional non linear adalah sebagai berikut

$$
\tilde{u}(x, t)=u_{0}(x, t)+u_{1}\left(x, t, c_{i}\right)
$$

3. Mendefinisikan fungsi homotopy sebagai berikut

$$
\begin{aligned}
& H\left[L\left(v\left(x, t, p, c_{i}\right)\right)+g(x, t), H\left(x, t, c_{i}\right), N\left(v\left(x, t, p, c_{i}\right)\right)\right] \\
& =L\left(u_{0}(x, t)\right)+g(x, t)+p\left[L\left(u_{1}\left(x, t, c_{i}\right)\right)-H\left(x, t, c_{i}\right) N\left(u_{0}(x, t)\right)\right]
\end{aligned}
$$

yang memenuhi kondisi saat $p=0$ yaitu

$$
L\left(u_{0}(x, t)\right)+g(x, t)=0
$$

dan kondisi saat $p=1$ yaitu

$$
H\left(x, t, c_{i}\right)\left[L(\tilde{u}(x, t))-H\left(x, t, c_{i}\right) N(\tilde{u}(x, t))\right]=0
$$

dimana $H\left(x, t, c_{i}\right) \neq 0$ adalah fungsi bantu dan fungsi orde $p^{2}, p^{3}, p^{4}$, dan seterusnya tidak perlu diperhitungkan. Dari (17) dan (18) diperoleh

$$
v\left(x, t, 0, c_{i}\right)=u_{0}(x, t), \quad v\left(x, t, 1, c_{i}\right)=\tilde{u}(x, t)
$$

4. Mengelompokkan koefisien dari $p^{0}$ dan $p^{1}$ pada (19) sehingga diperoleh persamaan untuk mencari $u_{0}(x, t)$ seperti pada (16) dan $u_{1}\left(x, t, c_{i}\right)$ sebagai berikut

$$
L\left(u_{1}\left(x, t, c_{i}\right)\right)=H\left(x, t, c_{i}\right) N\left(u_{0}(x, t)\right)
$$

5. Mendefinisikan operator nonlinear sebagai berikut

$$
N\left(u_{0}(x, t)\right)=\sum_{i=1}^{m} r_{i}(x, t) s_{i}(x, t)
$$

dimana $r(x, t)$ dan $s(x, t)$ adalah fungsi yang diketahui dan nilainya berdasarkan dari nilai $u_{0}(x, t)$ dan operator $N$. Solusi dari (24) merupakan penjumlahan dari solusi homogen dan solusi partikulir, tetapi pada beberapa kasus, hanya digunakan solusi partikulir saja [7].

6. Memerhatikan fungsi yang tidak diketahui $u_{1}\left(x, t, c_{i}\right)$ sebagai berikut

$$
u_{1}\left(x, t, c_{i}\right)=\sum_{j=1}^{m} H_{j}\left(x, t, r_{i}(x, t), c_{i}\right) s(x, t)
$$


dimana $H_{j}\left(x, t, r_{i}(x, t), c_{i}\right)$ merupakan kombinasi linear dari fungsi $r_{i}(x, t)$, misalkan $r_{1}=x^{2}+t^{2}$ maka $H_{1}=c_{1}\left(x^{2}+t^{2}\right)+c_{2}\left(x^{4}+t^{4}\right)+\cdots$. Kemudian menghitung nilai dari parameter kekonvergenan $c_{i}, i=$ $1,2,3, \ldots$, seperti pada (13),(14), dan (15) sehingga diperoleh fungsi solusi pendekatan dari (1).

\section{HASIL DAN PEMBAHASAN}

\subsection{Solusi persamaan gelombang fraksional non linear}

$$
\begin{gathered}
\frac{\partial^{\alpha} u(x, t)}{\partial x^{\alpha}}=u(x, t) \frac{\partial^{2} u(x, t)}{\partial t^{2}}+1-\frac{x^{2}+t^{2}}{2}, \quad 1<\alpha \leq 2, t \leq 1,0 \leq x \leq 1 \\
u(0, t)=\frac{t^{2}}{2}, \frac{\partial}{\partial x} u(0, t)=0
\end{gathered}
$$

Dengan mengubah (26) ke dalam bentuk (2), diperoleh

$$
\begin{gathered}
L(u(x, t))=\frac{\partial^{\alpha} u(x, t)}{\partial x^{\alpha}} \\
N(u(x, t))=-u(x, t) \frac{\partial^{2} u(x, t)}{\partial t^{2}} \\
g(x, t)=\frac{x^{2}+t^{2}}{2}-1
\end{gathered}
$$

Untuk solusi pendekatan menggunakan OHAM-1 dipilih fungsi bantu

$$
H\left(x, t, p, c_{i}\right)=p c_{1}+p^{2} c_{2}+p^{3} c_{3}
$$

dengan mensubstitusikan nilai diatas ke (3), lalu mengelompokkan parameter kecocokan $p$ dengan pangkat yang sama seperti (9), (10), dan (11) diperoleh

Masalah orde ke-nol

$$
\frac{\partial^{\alpha} u_{1}\left(x, t, c_{i}\right)}{\partial x^{\alpha}}=1-\frac{x^{2}+t^{2}}{2}
$$

Masalah orde ke-satu

$$
\begin{aligned}
\frac{\partial^{\alpha} u_{1}\left(x, t, c_{i}\right)}{\partial x^{\alpha}}= & -c_{1}\left(\frac{x^{\alpha}}{\Gamma(\alpha+1)}-\frac{x^{\alpha+2}}{\Gamma(\alpha+3)}-\frac{x^{\alpha} t^{2}}{\Gamma(\alpha+1)}+\frac{t^{2}}{2}+\right. \\
& \left.-\frac{x^{2 \alpha}}{\Gamma(\alpha+1)^{2}}+\frac{x^{2 \alpha+2}}{\Gamma(\alpha+1) \Gamma(\alpha+3)}+\frac{x^{2 \alpha} t^{2}}{2 \Gamma(\alpha+1)^{2}}\right)
\end{aligned}
$$

Dan seterusnya, sehingga solusi pendekatan menggunakan OHAM-1 adalah sebagai berikut

$$
\begin{aligned}
\tilde{u}\left(x, t, c_{i}\right)= & {\left[\frac{x^{\alpha}}{\Gamma(\alpha+1)}-\frac{x^{\alpha+2}}{\Gamma(\alpha+3)}-\frac{x^{\alpha} t^{2}}{2 \Gamma(\alpha+1)}+\frac{t^{2}}{2}\right] } \\
& +\left[c _ { 1 } \left(-\frac{\Gamma(2 \alpha+3) x^{3 \alpha+2}}{\Gamma(\alpha+1) \Gamma(\alpha+3) \Gamma(3 \alpha+3)}+\frac{\Gamma(2 \alpha+1) x^{3 \alpha}}{\Gamma(\alpha+1)^{2} \Gamma(3 \alpha+1)}\right.\right. \\
& +\frac{x^{2 \alpha+2}}{\Gamma(2 \alpha+3)}-\frac{x^{2 \alpha}}{\Gamma(2 \alpha+1)}-\frac{\Gamma(2 \alpha+1) x^{3 \alpha} t^{2}}{2 \Gamma(\alpha+1)^{2} \Gamma(3 \alpha+1)} \\
& \left.+\frac{x^{2 \alpha} t^{2}}{\Gamma(2 \alpha+1)}-\frac{x^{\alpha} t^{2}}{2 \Gamma(\alpha+1)}\right]+\cdots
\end{aligned}
$$

Selanjutnya adalah solusi pendekatan menggunakan OHAM-2. dari OHAM-1 diperoleh nilai $u_{0}(x, t)$ sebagai berikut

$$
u_{0}(x, t) \quad=\frac{x^{\alpha}}{\Gamma(\alpha+1)}-\frac{x^{\alpha+2}}{\Gamma(\alpha+3)}-\frac{x^{\alpha} t^{2}}{2 \Gamma(\alpha+1)}+\frac{t^{2}}{2}
$$


dan fungsi dari operator non linear $N$ untuk $u_{0}(x, t)$ sebagai berikut

$$
N\left(u_{0}(x, t)\right)=-u_{0}(x, t) \frac{\partial^{2}}{\partial t^{2}} u_{0}(x, t)
$$

Kemudian dipilih nilai dari $r_{1}(x, t)$ sebagai berikut

$$
r_{1}(x, t)=\left(1-\frac{x^{\alpha}}{\Gamma(\alpha+1)}\right)
$$

Berdasarkan (25), dipilih fungsi bantu $H\left(x, t, c_{i}\right)=H_{1}\left(x, t, r_{1}(x, t), c_{i}\right)$

$$
H\left(x, t, c_{i}\right)=c_{1}+c_{2} x^{\alpha}+c_{3} x^{2 \alpha}+c_{4} x^{3 \alpha}+c_{5} x^{4 \alpha}
$$

dan diperoleh nilai dari $u_{1}\left(x, t, c_{i}\right)$ sebagai berikut

$$
\begin{aligned}
\frac{\partial^{\alpha} u_{1}\left(x, t, c_{i}\right)}{\partial x^{\alpha}}= & \left(c_{1}+c_{2} x^{\alpha}+c_{3} x^{2 \alpha}+c_{4} x^{3 \alpha}+c_{5} x^{4 \alpha}\right)\left(-\frac{x^{\alpha}}{\Gamma(\alpha+1)}+\frac{x^{\alpha+2}}{\Gamma(\alpha+3)}+\frac{x^{\alpha} t^{2}}{\Gamma(\alpha+1)}\right. \\
& \left.-\frac{t^{2}}{2}+\frac{x^{2 \alpha}}{\Gamma(\alpha+1)^{2}}-\frac{x^{2 \alpha+2}}{\Gamma(\alpha+1) \Gamma(\alpha+3)}-\frac{x^{2 \alpha} t^{2}}{2 \Gamma(\alpha+1)^{2}}\right)
\end{aligned}
$$

sehingga solusi pendekatan menggunakan OHAM-2 adalah sebagai berikut

$$
\begin{aligned}
\tilde{u}\left(x, t, c_{i}\right)= & \frac{x^{\alpha}}{\Gamma(\alpha+1)}-\frac{x^{\alpha+2}}{\Gamma(\alpha+3)}-\frac{x^{\alpha} t^{2}}{2 \Gamma(\alpha+1)}+\frac{t^{2}}{2}+c_{1}\left(-\frac{x^{2 \alpha}}{\Gamma(2 \alpha+1)}\right. \\
& +\frac{x^{2 \alpha+2}}{\Gamma(2 \alpha+3)}+\frac{x^{2 \alpha} t^{2}}{\Gamma(2 \alpha+1)}-\frac{x^{\alpha} t^{2}}{\Gamma(\alpha+1)}+\frac{\Gamma(2 \alpha+1) x^{3 \alpha}}{\Gamma(\alpha+1)^{2} \Gamma(3 \alpha+1)} \\
& \left.-\frac{\Gamma(2 \alpha+3) x^{3 \alpha+2}}{\Gamma(\alpha+1) \Gamma(\alpha+3) \Gamma(3 \alpha+3)}-\frac{\Gamma(2 \alpha+1) x^{3 \alpha} t^{2}}{2 \Gamma(\alpha+1)^{2} \Gamma(3 \alpha+1)}\right)+\cdots
\end{aligned}
$$

\subsection{Kekonvergenan Barisan Fungsi Solusi Persamaan Gelombang Fraksional Non Linear}

Selanjutnya akan diperlihatkan bahwa barisan fungsi solusi dari persamaan gelombang fraksional nonlinear berorde $\left(\alpha_{n}, 2\right)$ yang konvergen ke $(\alpha, 2)$, akan konvergen ke fungsi solusi dari persamaan gelombang fraksional nonlinear berorde $(\alpha, 2)$. Dipilih barisan $\left(\alpha_{n}\right)=\left(\frac{2 n}{n+1}\right)$, dengan $\left(\alpha_{n}\right)$ barisan bilangan yang konvergen ke $\alpha=2$ sehingga persamaan gelombang fraksional non linear menjadi sebagai berikut

$$
\begin{aligned}
& \tilde{u}_{n}\left(x, t, c_{i}\right)= \frac{x^{\frac{2 n}{n+1}}}{\Gamma\left(\left(\frac{2 n}{n+1}\right)+1\right)}-\frac{x^{\frac{2 n}{n+1}+2}}{\Gamma\left(\left(\frac{2 n}{n+1}\right)+3\right)}-\frac{x^{\frac{2 n}{n+1}} t^{2}}{2 \Gamma\left(\left(\frac{2 n}{n+1}\right)+1\right)}+\frac{t^{2}}{2}+c_{1}\left(-\frac{x^{2 \frac{2 n}{n+1}}}{\Gamma\left(2\left(\frac{2 n}{n+1}\right)+1\right)}\right. \\
&+\frac{x^{2 \frac{2 n}{n+1}+2}}{\Gamma\left(2\left(\frac{2 n}{n+1}\right)+3\right)}+\frac{x^{2 \frac{2 n}{n+1}} t^{2}}{\Gamma\left(2\left(\frac{2 n}{n+1}\right)+1\right)}-\frac{x^{\frac{2 n}{n+1}} t^{2}}{2 \Gamma\left(\left(\frac{2 n}{n+1}\right)+1\right)} \\
&+\frac{\Gamma\left(2\left(\frac{2 n}{n+1}\right)+1\right) x^{3 \frac{2 n}{n+1}}}{\Gamma\left(\left(\frac{2 n}{n+1}\right)+1\right)^{2} \Gamma\left(3\left(\frac{2 n}{n+1}\right)+1\right)} \\
&-\frac{\Gamma\left(2\left(\frac{2 n}{n+1}\right)+3\right) x^{3 \frac{2 n}{n+1}+2}}{\Gamma\left(\left(\frac{2 n}{n+1}\right)+1\right) \Gamma\left(\left(\frac{2 n}{n+1}\right)+3\right) \Gamma\left(3\left(\frac{2 n}{n+1}\right)+3\right)} \\
&\left.-\frac{\Gamma\left(2\left(\frac{2 n}{n+1}\right)+1\right) x^{3 \frac{2 n}{n+1}} t^{2}}{2 \Gamma\left(\left(\frac{2 n}{n+1}\right)+1\right)^{2} \Gamma\left(3\left(\frac{2 n}{n+1}\right)+1\right)}\right)+\cdots
\end{aligned}
$$


Dengan orde dari fungsi solusi pendekatan $\left(\tilde{u}_{n}\left(x, t, c_{i}\right)\right)$ yaitu $n=2,3,4, \ldots$ diperoleh barisan fungsi solusi persamaan gelombang fraksional non linear dalam grafik berikut
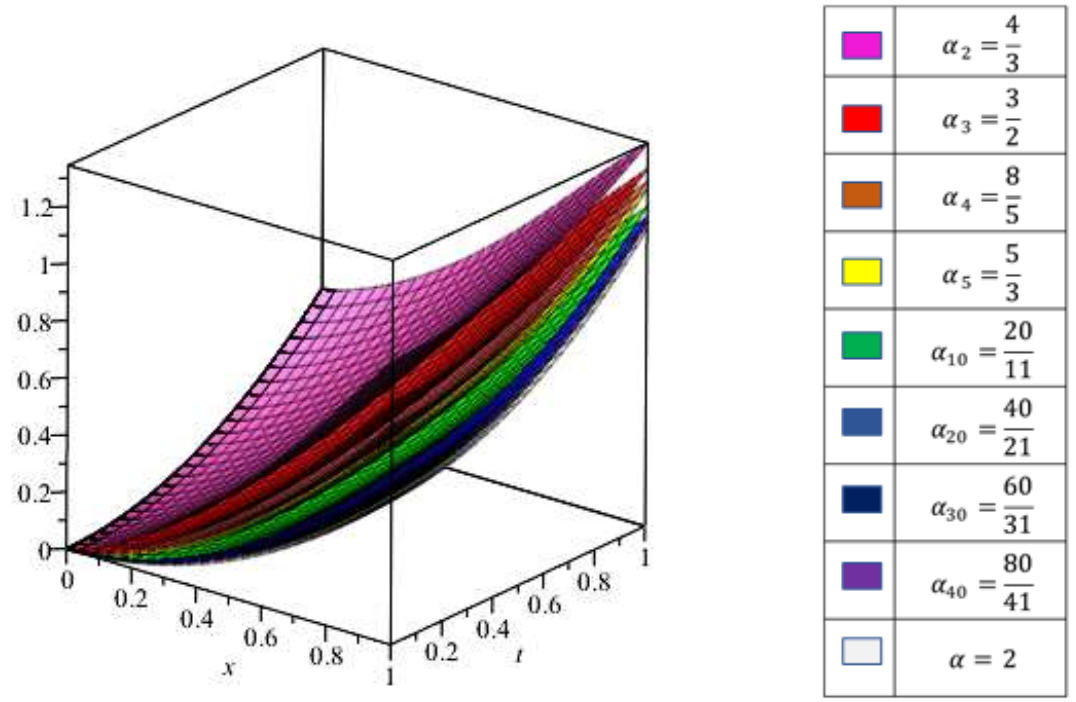

\section{Gambar 1. Grafik Barisan Fungsi Solusi Pendekatan Persamaan Gelombang Fraksional Nonlinear Menggunakan OHAM-2}

Berdasarkan gambar dapat dilihat jika $\left(\alpha_{n}, 2\right)$ konvergen ke $(\alpha, 2)$, maka barisan fungsi solusi pendekatan persamaan gelombang fraksional non linear bentuk pertama berode $\left(\alpha_{n}, 2\right)$ juga akan konvergen ke fungsi solusi pendekatan persamaan gelombang fraksional non linear orde $(\alpha, 2)$.

\subsection{Perbandingan Solusi Persamaan Gelombang Fraksional Non Linear}

Selanjutnya akan dihitung galat dari solusi pendekatan OHAM-1, OHAM-2, dan solusi eksak menggunakan MAPE sehingga diperoleh solusi pendekatan yang memiliki galat terkecil dengan solusi eksak. Perbandingan solusi dilakukan ketika (1) memiliki orde turunan $\alpha=2$ sehingga memiliki solusi sebagai berikut,

a. Solusi eksak

$$
u(x, t)=\frac{x^{2}+t^{2}}{2}
$$

b. Solusi pendekatan menggunakan OHAM-1

$$
\begin{aligned}
\tilde{u}\left(x, t, c_{i}\right) & =\left[\frac{x^{2}}{2}-\frac{x^{4}}{24}-\frac{x^{2} t^{2}}{4}+\frac{t^{2}}{2}\right] \\
& +\left[c_{1}\left(-\frac{x^{8}}{2688}+\frac{7 x^{6}}{720}-\frac{x^{4}}{24}-\frac{x^{6} t^{2}}{240}+\frac{x^{4} t^{2}}{24}-\frac{x^{2} t^{2}}{4}\right)\right] \\
& +\left[\left(c_{1}+c_{1}^{2}+c_{2}\right)\left(-\frac{x^{8}}{5376}+\frac{7 x^{6}}{720}-\frac{x^{4}}{24}-\frac{x^{6} t^{2}}{240}+\frac{x^{4} t^{2}}{24}-\frac{x^{2} t^{2}}{4}\right)\right. \\
& +c_{1}^{2}\left(-\frac{43 x^{12}}{10644480}+\frac{173 x^{10}}{1209600}-\frac{67 x^{8}}{40320}+\frac{7 x^{6}}{720}-\frac{x^{10} t^{2}}{21600}\right. \\
& \left.\left.+\frac{x^{8} t^{2}}{1120}-\frac{x^{6} t^{2}}{90}+\frac{x^{4} t^{2}}{24}\right)\right]+\cdots
\end{aligned}
$$

Dengan menggunakan (13),(14), dan (15) diperoleh nilai parameter kekonvergenan $c_{1}, c_{2}$, dan $c_{3}$ sehingga solusi persamaan gelombang fraksional menjadi 


$$
\begin{aligned}
\tilde{u}(x, t)= & \frac{x^{2}}{2}+\frac{t^{2}}{2}+(0,000425355512) x^{4}-(0,001501127495) x^{6} \\
& +(0,001577786769) x^{8}-(0,0005403616886) x^{10} \\
& +(0,00006209500718) x^{12}-(0,000003646708133) x^{14} \\
& +\left(7,947178556 \times 10^{-8}\right) x^{16}+(0,00255213302) t^{2} x^{2} \\
& -(0,00643340352) t^{2} x^{4}+(0,01224622287) t^{2} x^{6} \\
& -(0,003387392271) t^{2} x^{8}+(0,0004547304950) t^{2} x^{10} \\
& -(0,00002840462139) t^{2} x^{12}+(0,000001004234525) t^{2} x^{14}
\end{aligned}
$$

c. Solusi pendekatan menggunakan OHAM-2

$$
\begin{aligned}
\tilde{u}\left(x, t, c_{i}\right) & =\frac{x^{2}}{2}-\frac{x^{4}}{24}-\frac{x^{2} t^{2}}{4}+\frac{t^{2}}{2}+ \\
& +c_{1}\left(-\frac{x^{4}}{24}+\frac{7 x^{6}}{720}-\frac{x^{8}}{2688}-\frac{x^{6} t^{2}}{240}+\frac{x^{4} t^{2}}{24}-\frac{x^{2} t^{2}}{2}\right)+ \\
& +c_{2}\left(-\frac{x^{6}}{60}+\frac{7 x^{8}}{1344}-\frac{x^{10}}{4320}-\frac{x^{8} t^{2}}{448}+\frac{x^{6} t^{2}}{60}-\frac{x^{4} t^{2}}{24}\right)+ \\
& +c_{3}\left(-\frac{x^{8}}{112}+\frac{7 x^{10}}{2160}-\frac{x^{12}}{6336}-\frac{x^{10} t^{2}}{720}+\frac{x^{8} t^{2}}{112}-\frac{x^{6} t^{2}}{60}\right)+ \\
& +c_{4}\left(-\frac{x^{10}}{180}+\frac{7 x^{12}}{3168}-\frac{x^{14}}{8736}-\frac{x^{12} t^{2}}{1056}+\frac{x^{10} t^{2}}{180}-\frac{x^{8} t^{2}}{112}\right)+ \\
& +c_{5}\left(-\frac{x^{12}}{264}+\frac{7 x^{14}}{4368}-\frac{x^{16}}{11520}-\frac{x^{14} t^{2}}{1456}+\frac{x^{12} t^{2}}{264}-\frac{x^{10} t^{2}}{180}\right)
\end{aligned}
$$

Dengan menggunakan (13),(14), dan (15) diperoleh nilai parameter kekonvergenan $c_{1}, c_{2}, c_{3}, c_{4}$, dan $c_{5}$ sehingga solusi persamaan gelombang fraksional menjadi

$$
\begin{aligned}
\tilde{u}(x, t)= & \frac{x^{2}}{2}+\frac{t^{2}}{2}+(0.00685423366) x^{4}+(0,00804910807) x^{6} \\
& -(0,004467720256) x^{8}+(0,0002353652884) x^{10} \\
& +(0,0000385139212) x^{12}-(0,00006446825655) x^{14} \\
& +(0,000003921273760) x^{16}+(0,0411254025) t^{2} x^{2} \\
& -(0,00009427167) t^{2} x^{4}-(0,01236744090) t^{2} x^{6} \\
& +(0,002060007873) t^{2} x^{8}+(0,0000456196632) t^{2} x^{10} \\
& -(0,0001055529850) t^{2} x^{12}+(0,00003102546271) t^{2} x^{14}
\end{aligned}
$$

Selanjutnya dapat dilihat melalui nilai galat dengan menggunakan MAPE, dengan $\Delta x=0,1, \Delta t=0,1, N_{1}=$ 11 , dan $N_{2}=11$ dan grafik perbandingan fungsi solusi pendekatan menggunakan OHAM-1, OHAM-2, dan solusi eksak.

a. Grafik dan nilai MAPE untuk solusi pendekatan OHAM-1 dengan solusi eksak 

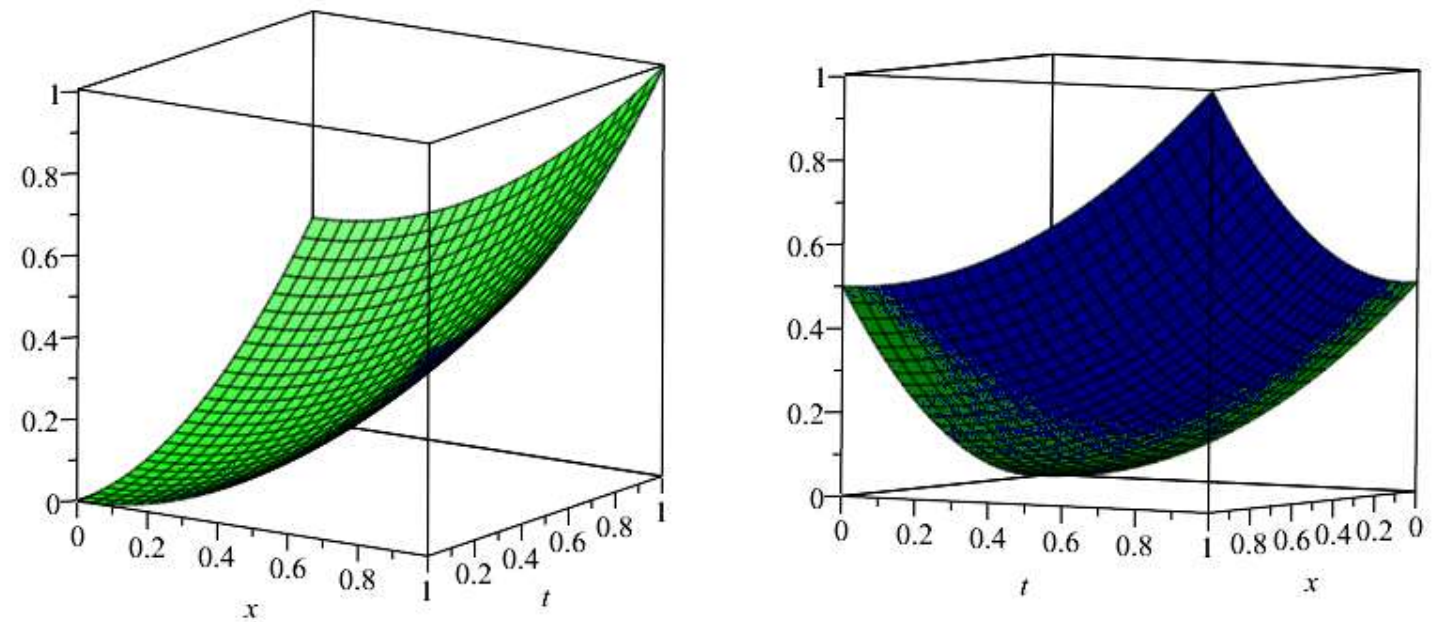

Gambar 2. Grafik Solusi Pendekatan Eksak

) Persamaan Gelombang Fraksional Non Linear Bentuk Kedua dan Menggunakan OHAM-1 ( $(u)$

$$
\begin{aligned}
M A P E & =\frac{100 \%}{N_{1} N_{2}} \sum_{t=1}^{N_{1}} \sum_{x=1}^{N_{2}}\left|\frac{A_{(x, t)}-F_{1(x, t)}}{A_{(x, t)}}\right| . \\
& =\frac{100 \%}{121} 0,07850447728=0,06487973329 \% .
\end{aligned}
$$

b. Grafik dan nilai MAPE untuk solusi pendekatan OHAM-2 dengan solusi eksak
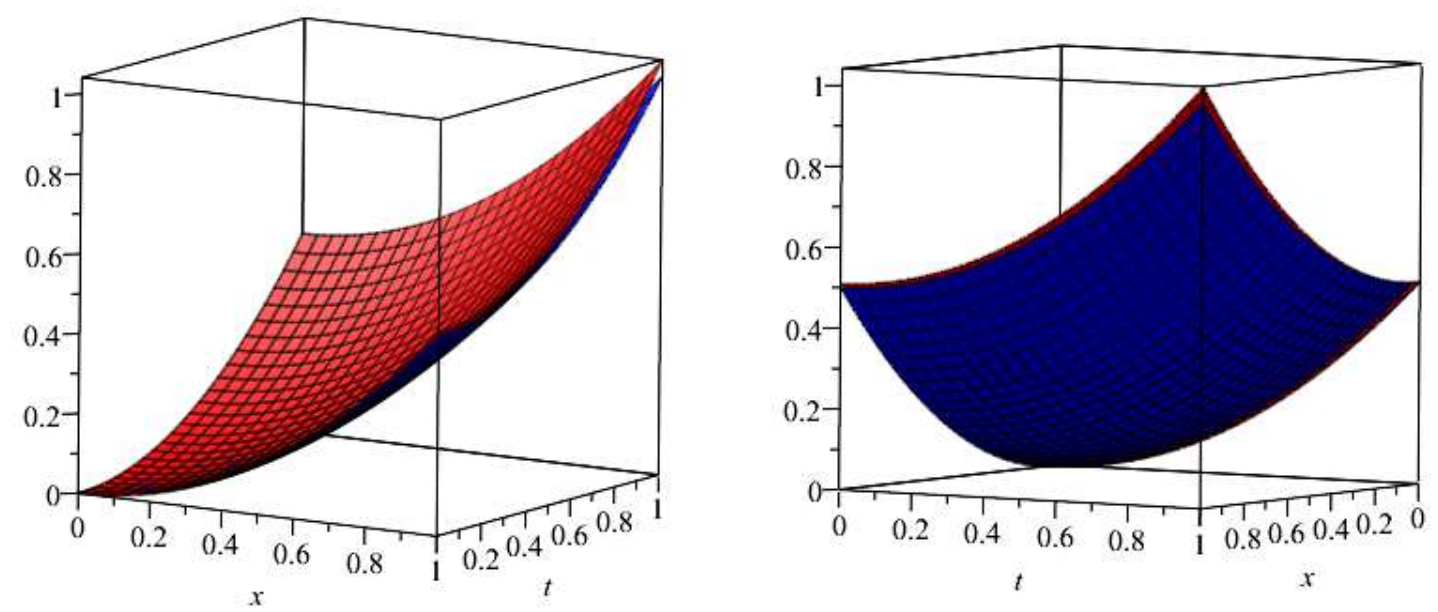

Gambar 3. Grafik Solusi Pendekatan Eksak ( $\square$ ) Persamaan Gelombang Fraksional Non Linear Bentuk Kedua dan Menggunakan OHAM-2( $)$

$$
\begin{aligned}
M A P E & =\frac{100 \%}{N_{1} N_{2}} \sum_{t=1}^{N_{1}} \sum_{x=1}^{N_{2}}\left|\frac{A_{(x, t)}-F_{2}(x, t)}{A_{(x, t)}}\right| . \\
& =\frac{100 \%}{121} 1,545795975=1,277517335 \% .
\end{aligned}
$$


c. Grafik perbandingan solusi pendekatan OHAM-1, OHAM-2, dan solusi eksak
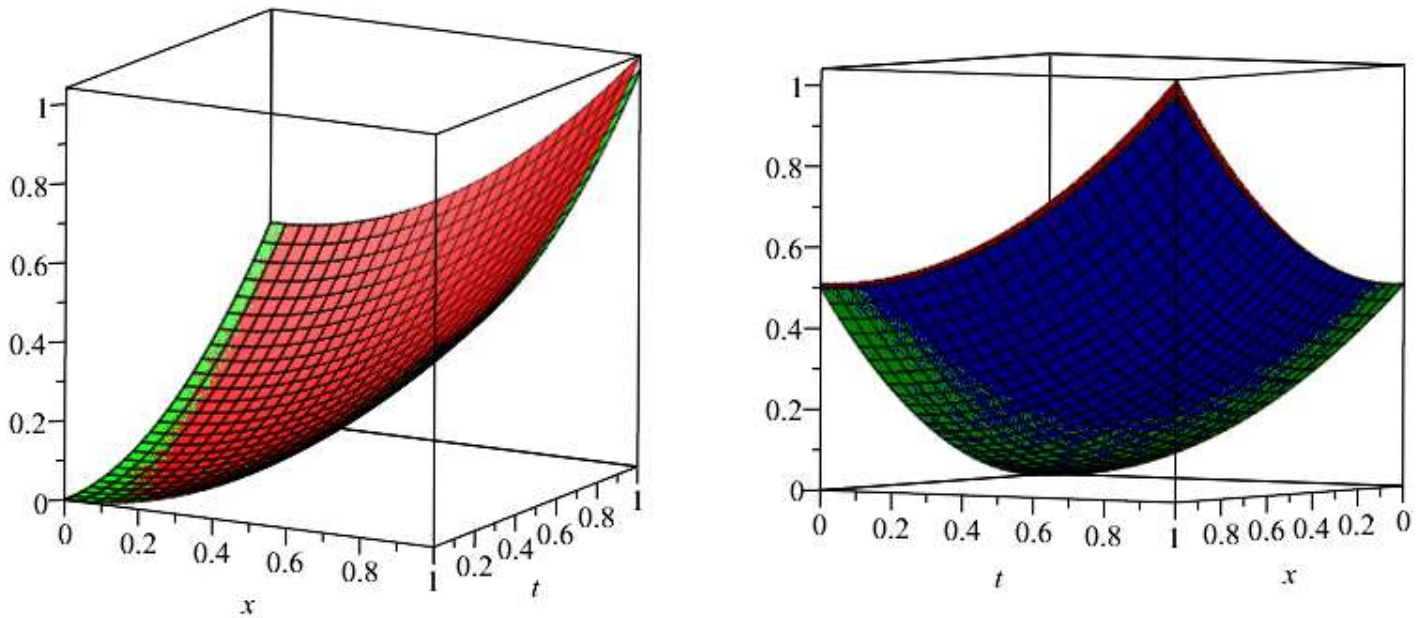

\section{Gambar 4. Grafik Solusi Pendekatan Eksak ( $)$ Persamaan Gelombang Fraksional Non Linear Bentuk Kedua, Menggunakan OHAM-1 ( $)$, Dan OHAM-2( $\square)$}

Dapat dilihat galat dari hasil perhitungan menggunakan MAPE antara solusi pendekatan persamaan gelombang fraksional dengan menggunakan OHAM-1 dan OHAM-2 dengan solusi eksak untuk $0 \leq x \leq 1$, $0 \leq t \leq 1$ adalah $0,06487973329 \%$ dan 1,277517335\% dimana nilai tersebut masih dikategorikan sangat baik [8].

\section{KESIMPULAN}

Berdasarkan hasil dan pembahasan pada penelitian ini penulis dapat menyimpulkan bahwa:

1. Persamaan gelombang fraksional nonlinear dapat dicari dan mempunyai solusi pendekatan dengan menggunakan OHAM-2.

2. Kekonvergenan barisan fungsi solusi persamaan gelombang fraksional nonlinear berorde $\left(\alpha_{n}, 2\right)$ adalah konvergen ke fungsi solusi pendekatan persamaan gelombang fraksional non linear berorde $(\alpha, 2)$.

3. Solusi pendekatan yang dicari menggunakan OHAM-2 lebih sederhana namun belum lebih baik dibandingkan menggunakan OHAM-1, namun pemilihan fungsi bantu dan metode untuk menghitung nilai residu dapat memengaruhi nilai galat pada OHAM-2 sehingga dapat memberikan solusi pendekatan yang lebih baik.

\section{DAFTAR PUSTAKA}

[1] Loverro, A., "Fractional calculus: history, definitions and applications for the engineer". Rapport technique, University of Notre Dame: Department of Aerospace and Mechanical Engineering, pp.1-28. 2004.

[2] Ghazanfari, B., Ghazanfari, A.G. and Fuladvand, M., "Modification of the homotopy perturbation method for numerical solution of nonlinear wave and system of nonlinear wave equations". The Journal of Mathematics and Computer Science, 3(2), pp.212-224. 2011.

[3] Ghiasi, E.K. and Saleh, R., "Optimal homotopy asymptotic method-based Galerkin approach for solving generalized Blasius boundary value problem". Journal of Advanced Physics, 7(3), pp.408-411. 2018.

[4] Aminikhah, H. and Jamalian, A., "Numerical approximation for nonlinear gas dynamic equation". International Journal of Partial Differential Equations, 2013. 2013.

[5] Ullah, H., Islam, S., Dennis, L.C.C., Abdelhameed, T.N., Khan, I. and Fiza, M., "Approximate solution of twodimensional nonlinear wave equation by optimal homotopy asymptotic method". Mathematical Problems in Engineering, 2015. 2015.

[6] Jafari, H., Chun, C., Seifi, S. and Saeidy, M., "Analytical solution for nonlinear gas dynamic equation by homotopy analysis method". Applications and Applied mathematics, 4(1), pp.149-154. 2009. 
[7] Ali, L., Islam, S., Gul, T., Khan, I. and Dennis, L.C.C., "New version of optimal homotopy asymptotic method for the solution of nonlinear boundary value problems in finite and infinite intervals". Alexandria Engineering Journal, 55(3), pp.2811-2819. 2016.

[8] Gilliland, M., 2010. The business forecasting deal: exposing myths, eliminating bad practices, providing practical solutions (Vol. 27). John Wiley \& Sons.

[9] Kimeu, J.M., Fractional calculus: Definitions and applications. 2009.

[10] He, J.H., "Homotopy perturbation method: a new nonlinear analytical technique". Applied Mathematics and computation, 135(1), pp.73-79. 2003.

[11] Debnath, L., Nonlinear partial differential equations for scientists and engineers. Springer Science \& Business Media. 2011.

[12] Nawaz, R., Ullah, H., Islam, S. and Idrees, M., "Application of optimal homotopy asymptotic method to Burger equations". Journal of Applied Mathematics, 2013. 2013.

[13] Ray, S.S. and Gupta, A.K., Wavelet Methods for Solving Partial Differential Equations and Fractional Differential Equations. CRC Press. 2018.

[14] Sarwar, S., Alkhalaf, S., Iqbal, S. and Zahid, M.A., "A note on optimal homotopy asymptotic method for the solutions of fractional order heat-and wave-like partial differential equations". Computers \& Mathematics with Applications, 70(5), pp.942-953. 2015.

[15] Sarwar, S. and Iqbal, S., "Exact solutions of the non-linear fractional Klein-Gordon equation using the optimal homotopy asymptotic method". Nonlinear Sci. Lett. A, 8(4), pp.365-373. 2017.

[16] Liao, S., "Homotopy analysis method: a new analytical technique for nonlinear problems". Communications in Nonlinear Science and Numerical Simulation, 2(2), pp.95-100. 1997.

[17] Kim, S. and Kim, H., "A new metric of absolute percentage error for intermittent demand" forecasts. International Journal of Forecasting, 32(3), pp.669-679. 2016.

[18] Kisela, T., Fractional differential equations and their applications. Faculty of Mechanical Engineering Institute of Mathematics. 2008.

[19] Roubíček, T., Nonlinear partial differential equations with applications (Vol. 153). Springer Science \& Business Media. 2013.

[20] Marinca, V. and Herişanu, N., "Application of optimal homotopy asymptotic method for solving nonlinear equations arising in heat transfer". International communications in heat and mass transfer, 35(6), pp.710-715. 2008. 
